\title{
Effect of physician-provided education on the quality of bowel preparation
}

\author{
B. Dikkanoğlu' 1 A.E. Duman², S. Hülagü \\ (1) Kocaeli University, Faculty of Medicine, Department of Internal Medicine, Izmit, Turkey ; (2) Kocaeli University, Faculty of Medicine, Department of Gastroenterology,
} Izmit, Turkey

\begin{abstract}
Background and study aims: Inadequate bowel preparation in patients scheduled for colonoscopy is an important problem. In our study, we aimed to investigate the effect of physician-provided bowel preparation education on the quality of bowel preparation and process.

Patients and methods: A total of 150 outpatients who were referred to Kocaeli University Medical Faculty Hospital Gastroenterology Unit for colonoscopy between May 2019 and October 2019 were enrolled in our prospective, endoscopist-blinded study. Patients were divided into two groups. Group 1 (education group) included 73 patients who received 10 minutes of verbal information from a physician in addition to a written information form. Group 2 (control group) included 75 patients who received information from a medical secretary in addition to a written information form. During colonoscopy, the quality of bowel preparation was assessed using the Boston bowel preparation scale (BBPS). A BBPS score $\geq 5$ was considered adequate bowel preparation. The mean BBPS score, polyp detection rate, cecal intubation rate and time, and procedure time were also evaluated.

Results: The rate of adequate bowel preparation (BBPS score $\geq 5$ ) was $90.4 \%$ and $74.7 \%$ in groups 1 and 2 , respectively ( $p=$ 0.021). The odds ratio for having a BBPS score $\geq 5$ in the education group was 3.199 compared with the control group $(95 \%$ confidence interval $=1.254-8.164 ; p=0.015)$. The cecal intubation rates were $91.8 \%$ and $88 \%$ in groups 1 and 2 , respectively $(p>0.05)$. The cecal intubation time, procedure time, and adenoma detection rates were similar between the groups. The relationships of age, education level, sex, diabetes mellitus, medicine use, procedure time, and intraabdominal surgery with inadequate bowel preparation were analysed using a logistic regression model. Univariate and multivariate analyses revealed no significant factors associated with inadequate bowel preparation.

Conclusions: Patient education on the bowel preparation process via a physician improved the quality of bowel preparation. (Acta gastroenterol. belg., 2021, 84, 407-410).
\end{abstract}

Key words: Bowel preparation, colonoscopy, patient education.

\section{Introduction}

Colonoscopy is the most efficient method for colorectal cancer screening in moderate-risk patients over age 50 years and in high-risk young patients (1). To visualize mucosal lesions during the colonoscopy procedure, adequate bowel preparation is essential. Inadequate bowel preparation has been reported in up to $30 \%$ of patients (2). The diagnostic accuracy and therapeutic safety of colonoscopy depend on bowel cleanliness and the nature of bowel preparation (3). It is important that patients are educated and involved in the process of preparing for colonoscopy. Effective education significantly improves the quality of bowel preparation $(4,5)$. Recent international guidelines suggest the importance of providing both verbal and written instructions for all parts of the colonoscopy preparation process $(6,7)$. Inadequate bowel preparation for colonoscopy can lead to missed lesions, cancelled procedures, prolonged processing time, increased costs, and potential increases in adverse event rates $(8,9)$.

Our aim was to determine the frequency of inadequate bowel preparation in our clinic and to analyse the effect of physician-provided personalized education on colonoscopy preparation on the quality of bowel cleansing in patients scheduled for outpatient colonoscopy. The results obtained in this study will aid in achieving optimal bowel preparation, reducing the number of unnecessary procedures, increasing the success of the colonoscopy, and consequently achieving benefits in terms of patient and procedure costs.

\section{Materials and methods}

\section{Patients and Methods}

In this study, 150 outpatients who were referred to Kocaeli University Medical Faculty Hospital Gastroenterology Unit between May 2019 and October 2019 for colonoscopy procedures for any reason were enrolled. The study was approved by the local ethical committee (Approval number: 03.04.2019/KOU GOKAEK 2019/ 06.07/2019/88).

Polyethylene glycol (PEG) electrolyte lavage solution was the recommended bowel cleansing method. Demographic information and histories of systemic disease, surgery, and drug use in all patients were examined.

Patients were divided into two groups. Group 1 (education group) included 75 patients who received 10 minutes of verbal information from a physician in addition to a written information form. Group 2 (control group) included 75 patients who received information from a medical secretary in addition to a written information form. The importance of bowel preparation and how to perform bowel preparation were explained to the patients. During the education, the pre-colonoscopy diet, importance of sufficient hydration, and correct

Correspondence to : Ali Erkan Duman, Department of Gastroenterology, Faculty of Medicine, Kocaeli University, Umuttepe Yerleşkesi, 41001, Izmit/ Kocaeli, Turkey. Fax : +90-262-3037003.

E-mail : dralierkanduman@hotmail.com

Submission date : 27/09/2020

Acceptance date : 16/02/2021 
timing of taking PEG were explained. The importance of bowel preparation was emphasized; inadequate bowel preparation can result in missed lesions and the need for a repeat colonoscopy. Patients with a known history of colorectal cancer, under 18 years of age, with mental retardation, with ulcerative colitis or Crohn's disease, or with a history of major abdominal surgery and inpatients were excluded from the study. Patients capable of using PEG electrolyte lavage solution completely were included in the study.

As routine preparation, all patients scheduled for colonoscopy were asked to avoid fibrous foods 3 days before the procedure, and a diet of clear liquids was planned for the last day. The PEG solution was diluted with 41 water; the first half was taken at 18:00 the day before the procedure, with $240 \mathrm{ml}$ (one cup) taken every 10 minutes, and the second half was taken at 22:00. Clear fluid intake was stopped during the last 2 hours before the procedure.

All colonoscopies were performed using a Fujinon brand colonoscope by a senior experienced endoscopist who was blinded to the groups. During the colonoscopy procedure, the physician evaluated the bowel cleansing according to the BBPS scale. The physician assigned a score of 0-3 separately for the three segments of the bowel, giving a total score of $0-9$. The scoring system was as follows: 0 (inadequate): unprepared colonic segment in which the mucosa cannot be assessed due to the presence of stools ; 1 (poor): visibility of some of the mucosa in the colonic segment but poor visibility of other areas due to staining, residual stool, and/or opaque fluid; 2 (good): visible colonic mucosa but minor residue, minor stool, and/or opaque liquid particles present ; 3 (excellent): a good view of the entire colonic mucosa, with no residue, minor stool, or opaque liquid fragments. Previous validation studies have shown that a BBPS score $\geq 5$ is associated with a higher polyp detection rate and is considered adequate bowel preparation (10). Intravenous midazolam was used for sedation.

The reason for the colonoscopy procedure, drugs used, start time of the colonoscopy, time to reach the cecum, duration of the procedure, removal of any polyps, complications, and the bowel cleansing BBPS score were recorded.

\section{Statistical analysis}

Statistical evaluation was performed using IBM SPSS 20.0 (IBM Corp., Armonk, NY, USA). The distribution of the data was evaluated using the KolmogorovSmirnov test. Numerical variables are expressed as means \pm standard deviation and categorical variables as frequencies (percentage). Comparisons between groups were performed using Student's t test when the distribution was normal and the Mann-Whitney $U$ test otherwise. Differences between categorical variables were evaluated by the chi-square test. Logistic regression analysis was used to determine the relationships of
Table 1. - Sociodemographic characteristics of the patients

\begin{tabular}{|l|l|l|l|}
\hline & Education group & Control group & p value \\
\hline Age (mean \pm SD) & $51.78 \pm 15.07$ & $53.59 \pm 14.04$ & 0.452 \\
Sex (\%) & & & 0.413 \\
Female & $35(47.9 \%)$ & $41(54.7 \%)$ & \\
Male & $38(52.1 \%)$ & $34(45.3 \%)$ & \\
BMI (mean \pm SD) & $28.02 \pm 4.95$ & $27.16 \pm 5.11$ & 0.30 \\
Education level (\%) & & & 0.161 \\
Illiterate & $4(5.5 \%)$ & $4(5.3 \%)$ & \\
Literate & $1(1.4 \%)$ & $4(5.3 \%)$ & \\
Primary school graduate & $38(52.1 \%)$ & $38(50.7 \%)$ & \\
High school graduate & $9(12.3 \%)$ & $16(21.3 \%)$ & \\
Graduated from university & $21(28.8 \%)$ & $13(17.3 \%)$ & \\
Medical disease (\%) & $50(68.5 \%)$ & $52(69.3 \%)$ & 1.000 \\
Diabetes mellitus (\%) & $16(21.9 \%)$ & $12(16 \%)$ & 0.478 \\
Constipation $(\%)$ & $16(21.9 \%)$ & $25(33.3 \%)$ & 0.171 \\
Prior abdominal surgery $(\%)$ & $28(38.4 \%)$ & $39(52 \%)$ & 0.095 \\
\hline
\end{tabular}

various factors with the variable of interest. In tests of bidirectional hypotheses, $\mathrm{p}<0.05$ was considered sufficient for statistical significance.

\section{Results}

In our study, 75 outpatients were in the education group and 75 outpatients in the control group. Two of 75 patients in the education group were excluded from the study because of procedure-related intolerance. The general characteristics of the patients included in the study are shown in Table 1 . Of the 73 patients in the education group informed by the physician, 38 were male $(52.1 \%)$ and 35 female $(47.9 \%)$. Of the 75 patients in the control group, 34 were male $(45.3 \%)$ and 41 female (54.7\%). The mean age was $51.78 \pm 15.07$ years in the education group and $53.59 \pm 14.04$ years in the control group.

The cecum could be intubated in $67(91.8 \%)$ of the 73 patients in the education group and $66(88 \%)$ of the 75 patients in the control group, with no statistically significant difference between the two groups ( $p>0.05)$. The cecal intubation time was similar between the two groups: $7.4473 \pm 3.55$ minutes in the education group and $8.1975 \pm 4.55$ minutes in the control group $(\mathrm{p}>0.05)$.

The proportion of patients with a BBPS score $\geq 5$ was $90.4 \%$ in the education group and $74.7 \%$ in the control group, with a significant difference between the groups $(p=0.021)$. There was also a significant difference in the mean BBPS score between the groups: $6.51 \pm 2.17$ in the education group and $5.41 \pm 2.63$ in the control group ( $p$ $=0.004)$.

The right colon BBPS score was $1.92 \pm 0.829$ in the education group and $1.57 \pm 0.91(p=0.013)$ in the control group; the left colon BBPS score was $2.33 \pm 0.728$ in the education group and $1.84 \pm 0.959$ in the control group $(p=0.001)$. There was no significant difference in the transverse colon BBPS scores between the groups ( $p$ $>0.05$ ). The adenoma detection rate was $23.3 \%$ in the education group and $25.3 \%$ in the control group, with no significant difference $(\mathrm{p}>0.05)$ 
Table 2. - The effect of physician provided patient education on bowel preparation and colonoscopy

\begin{tabular}{|l|l|l|l|}
\hline & Education group & Control group & p value \\
\hline Cecal intubation (\%) & $67(91.8 \%)$ & $66(88 \%)$ & 0.624 \\
Intubation time (minutes) & $7.44 \pm 3.55$ & $8.19 \pm 4.55$ & 0.478 \\
Procedure time (minutes) & $17.75 \pm 8.56$ & $20.25 \pm 11.38$ & 0.245 \\
BBPS $\geq 5(\%)$ & $66(90.4 \%)$ & $56(74.7 \%)$ & 0.021 \\
Total BBPS score & $6.51 \pm 2.17$ & $5.41 \pm 2.63$ & 0.004 \\
Right colon score & $1.92 \pm 0.829$ & $1.57 \pm 0.91$ & 0.013 \\
Transverse colon score & $2.29 \pm 0.79$ & $2 \pm 0.97$ & 0.075 \\
Left colon score & $2.33 \pm 0.728$ & $1.84 \pm 0.959$ & 0.001 \\
Adenoma detection rate (\%) & $17(23.3 \%)$ & $19(25.3 \%)$ & 0.922 \\
\hline
\end{tabular}

In univariate analyses using a logistic regression model, the odds ratio for having a BBPS score $\geq 5$ in the education group was 3.199 compared with the control group $(95 \%$ confidence interval $=1.254-8.164 ; \mathrm{p}=$ $0.015)$.

The relationships of factors such as age, education level, sex, presence of diabetes mellitus, drug use, time of colonoscopy, and intraabdominal surgery history with inadequate bowel preparation were analysed (Table 3). No significant relationships were detected in the univariate or multivariate analyses.

\section{Discussion}

In our study, we observed significantly higher quality of bowel preparation in outpatients who received education by a physician pre-colonoscopy. In a previous study, the reason for suboptimal bowel preparation was due the patient's lack of understanding of its importance, lack of confidence in the ability to follow the instructions, and confusion about the diet before colonoscopy (11).

Previous evaluations of interventions to increase the effectiveness of colonoscopy preparation quality include the studies by Rosenfeld et al. (12) on written instruction in addition to verbal instruction, Liu et al. (5) on telephone re-education regarding the details of bowel preparation on the day before colonoscopy, and Griffin et al. (13) on interactive voice-response systems to ensure that patients attend appointments. The interventions used in these studies improved bowel preparation quality. The European Society of Gastrointestinal Endoscopy (ESGE) recommends that written and verbal information about bowel preparation be delivered together by healthcare professionals (6).

In our study, we evaluated the quality of bowel preparation using the BBPS score. We considered BBPS $\geq$ 5 as adequate bowel preparation. The proportion of bowel preparations with a BBPS score $\geq 5$ differed significantly between the two groups: $90.4 \%$ in the education group versus $74.7 \%$ in the control group. In a similar study by Shieh et al. (14), the rates were $97.4 \%$ (39 patients) in the education group and $80 \%$ (60 patients) in the control group. The small number of samples in this study and the lack of randomization may have affected the results. In previous studies, inadequate bowel preparation was found in $21.7 \%$ and $30 \%$ of patients, while the inadequate bowel preparation rate in our control group was $25.3 \%$.

In our study, the control and education groups were homogeneous, and there were no statistically significant differences between the two groups in terms of age, sex, BMI, chronic disease, chronic constipation, diabetes mellitus, or intra-abdominal surgery history.

While there was a significant difference in the right and left colon BBPS scores between the groups, there was no significant difference in the transverse colon BBPS score. Shieh et al. (14) detected significant differences between the left colon and transverse colon.

Successful cecal intubation rate is the most important indicator of colonoscopy quality (15). According to the

Table 3. - Risk factors associated with poor bowel preparation according to univariate and multivariate analyses

\begin{tabular}{|c|c|c|c|c|c|c|c|c|}
\hline Patient factors $\mathrm{Qu}$ & $\begin{array}{l}\text { Quality of bowel } \\
\text { Inadequate } \\
n=26\end{array}$ & $\begin{array}{l}\text { reparation, } n(\%) \\
\text { Adequate } \\
n=122\end{array}$ & Unadjusted OR & $95 \% \mathrm{CI}$ & $\mathrm{p}$ value & Adjusted OR & $95 \% \mathrm{CI}$ & p. value \\
\hline Age $<65$ years & $18(15.5 \%)$ & $98(84.5 \%)$ & 1.00 & & & & & \\
\hline$\geq 65$ years & $8(25 \%)$ & $24(75 \%)$ & 1.815 & $0.705-4.669$ & 0.216 & 1.131 & $0.340-3.759$ & 0.841 \\
\hline Sex Female & $11(14.5 \%)$ & $65(85.5 \%)$ & 1.00 & & & & & \\
\hline Male & $15(20.8 \%)$ & $57(79.2 \%)$ & 1.555 & $0.661-3.658$ & 0.312 & 1.869 & $0.688-5.073$ & 0.220 \\
\hline \multicolumn{9}{|l|}{ Education level } \\
\hline$\geq$ High school & ol $9(15.3 \%)$ & $50(84.7 \%)$ & 1.00 & & & & & \\
\hline$<$ High school & ol $17(19.1 \%)$ & $72(80.9 \%)$ & 1.312 & $0.541-3.178$ & 0.548 & 1.423 & $0.498-4.067$ & 0.510 \\
\hline \multicolumn{9}{|l|}{ Diabetes mellitus } \\
\hline No & $20(16.7 \%)$ & $100(83.3 \%)$ & 1.00 & & & & & \\
\hline Yes & $6(21.4 \%)$ & $22(78.6 \%)$ & 1.364 & $0.491-3.791$ & 0.522 & 1.833 & $0.569-5.908$ & 0.310 \\
\hline \multicolumn{9}{|l|}{ Drug use } \\
\hline No & $8(17.8 \%)$ & $37(82.2 \%)$ & 1.00 & & & & & \\
\hline Yes & $18(17.5 \%)$ & $85(82.5 \%)$ & 0.979 & $0.391-2.453$ & 0.965 & 0.829 & $0.265-2.594$ & 0.748 \\
\hline \multicolumn{9}{|l|}{ Timing of colonoscopy } \\
\hline Morning & $10(17.2 \%)$ & $48(82.8 \%)$ & 1.00 & & & & & \\
\hline Evening & $16(17.8 \%)$ & $74(82.2 \%)$ & 1.038 & $0.435-2.476$ & 0.933 & 1.383 & $0.535-3.577$ & 0.503 \\
\hline \multicolumn{9}{|c|}{ Previous abdominal surgery } \\
\hline No & $11(13.6 \%)$ & $70(86.4 \%)$ & 1.00 & & & & & \\
\hline Yes & $15(22.4 \%)$ & $52(77.6 \%)$ & 1.836 & $0.779-4.324$ & 0.165 & 1.720 & $0.653-4.532$ & 0.273 \\
\hline
\end{tabular}


latest guidelines of the American Society for Gastrointestinal Endoscopy and American College of Gastroenterology, updated in 2015, colonoscopists should be able to perform cecal intubation in over $90 \%$ of all colonoscopies and over $95 \%$ of colonoscopies performed for screening in healthy adults (16). In our study, the cecal intubation rates were $88 \%$ in the control group and $91.8 \%$ in the education group. The reason for the low cecal intubation rates may be due to the inadequate bowel cleansing in some patients.

In the study performed by Shieh et al. (14), the cecal intubation time was 8.7 minutes in the education group and 9.2 minutes in the control group, compared with 7.44 and 8.19 minutes in the education and control groups, respectively, in our study.

Another indicator of colonoscopy quality is the adenoma detection rate. According to the latest guidelines of the American Society for Gastrointestinal Endoscopy and American College of Gastroenterology, the adenoma detection rate should be at least $25 \%$ in patients over 50 years undergoing screening colonoscopy (16). In our study, the rates were $25.3 \%$ in the control group and $23.3 \%$ in the education group.

Inadequate preparation for colonoscopy can lead to prolonged procedure times and failure to detect pathologies (17). Unsuccessful procedures should be reevaluated by computed tomographic colonography or colonoscopy. This situation is with markedly increased costs and some risks to the patient $(18,19)$.

In a review by Kurlander et al. (20), the cost effectiveness of education provided by a physician was estimated to be lower than that of education provided by medical assistant staff, videos, or brochures. Information should be accessible across a full range of ages and socioeconomic statuses, and interventions that can be performed while a patient is present in the clinic may be more reliable than additional interventions given later, depending on the patient.

Our study has some limitations. The number of patients was relatively low, complete randomization was not performed (quasi-experimental method), and a splitdose regimen was not used for bowel cleansing.

Our results indicate that information on the bowel preparation process delivered to the patient by the physician increases the bowel preparation quality. Accordingly, it reduces the procedure time and the risk of procedure delays. The education and written instructions regarding bowel preparation are simple, feasible, safe, and inexpensive.

\section{Conflict of interests}

None declared.

\section{References}

1. REX D.K., BOLAND C.R., DOMINITZ J.A., GIARDIELLO F.M., JOHNSON D.A., KALTENBACH T. et al. Colorectal cancer screening : recommendations for physicians and patients from the US Multi-Society Task Force on Colorectal Cancer. Gastroenterology, 2017, 153.1 : 307-323.

2. SWEETSER S., BARON T.H. Optimizing bowel cleansing for colonoscopy. Mayo Clin. Proc., 2015, 90 (4) : 520-526.

3. REX D.K., PETRINI J.L., BARON T.H., CHAK A., COHEN J., DEAL S.E. et al. ASGE/ACG Taskforce on Quality in Endoscopy. Quality indicators for colonoscopy. Am J Gastroenterol., 2006, 101 : 873- 885.

4. SERPER M., GAWRON A.J., SMITH S.G., PANDIT A.A., DAHLKE A.R., BOJARSKI E.A. et al. Patient factors that affect quality of colonoscopy preparation. Clinical Gastroenterology and Hepatology, 2014, 12.3 : 451457.

5. LIU X., LUO H., ZHANG L., LEUNG F.W., LIU Z., WANG X. et al. Telephone-based re-education on the day before colonoscopy improves the quality of bowel preparation and the polyp detection rate: a prospective, colonoscopist-blinded, randomised, controlled study. Gut, 2014, 63.1 : 125130.

6. HASSAN C., BRETTHAUER M., KAMINSKI M.F., POLKOWSKI M., REMBACKEN B., SAUNDERS B. et al. Bowel preparation for colonoscopy: European Society of Gastrointestinal Endoscopy (ESGE) guideline. Endoscopy, 2013, 45 : 142-150.

7. JOHNSON D.A., BARKUN A.N., COHEN L.B., DOMINITZ J.A., KALTENBACH T., MARTEL M. et al. Optimizing adequacy of bowel cleansing for colonoscopy: recommendations from the US multi-society task force on colorectal cancer. Gastroenterology, 2014, 147 : 903-924.

8. FROEHLICH F., WIETLISBACH V., GONVERS J.J., BURNAND B., VADER J.P. Impact of colonic cleansing on quality and diagnostic yield of colonoscopy: the European Panel of Appropriateness of Gastrointestinal Endoscopy European multicenter study. Gastrointestinal Endoscopy, 2005, $61: 378-384$.

9. MENEES S.B., KIM H.M., ELLIOTT E.E., MICKEVICIUS J.L., GRAUSTEIN B.B., SCHOENFELD P.S. The impact of fair colonoscopy preparation on colonoscopy use and adenoma miss rates in patients undergoing outpatient colonoscopy. Gastrointestinal Endoscopy, 2013, 78 : 510-516.

10. SEO E.H., KIM T.O., PARK M.J., JOO H.R., HEO N.Y., PARK J. et al. Optimal preparation-to-colonoscopy interval in split-dose PEG bowel preparation determines satisfactory bowel preparation quality: an observational prospective study. Gastrointest Endosc., 2012, 75 : 583-590.

11. HILLYER G.C., BASCH C.H., BASCH C.E., LEBWOHL B., KASTRINOS F., INSEL B.J. et al. Gastroenterologists' perceived barriers to optimal precolonoscopy bowel preparation: results of a national survey. Journal of Cancer Education, 2012, 27 (3) : 526-532.

12. ROSENFELD G., KRYGIER D., ENNS R.A., SINGHAM J., WIESINGER H., BRESSLER B. et al. The impact of patient education on the quality of inpatient bowel preparation for colonoscopy. Can. J. Gastroenterol,. 2010, 24 : $543-546$

13. GRIFFIN J.M., HULBERT E.M., VERNON S.W., NELSON D., HAGEL E.M., NUGENT S. et al. Improving endoscopy completion: effectiveness of an interactive voice response system. American Journal of Managed Care, 2011, 17 (3) : 199-208.

14. SHIEH T., CHEN M., CHANG C., HUNG C., HU K., KUO Y. et al. Effect of physician-delivered patient education on the quality of bowel preparation for screening colonoscopy. Gastroenterology Research and Practice, Volume 2013.

15. PARK H.J., HONG H.J., KIM H.S., KIM B.R., PARK S.Y., JO K.W. et al. Predictive factors affecting cecal intubation failure in colonoscopy trainees. BMC Medical Education, 2013, 13.1: 5

16. REX D.K., SCHOENFELD P.S., COHEN J., PIKE I.M., ADLER D.G., FENNERTY M.B. et al. Quality indicators for colonoscopy. Gastrointestinal Endoscopy, 2015, 81.1 : 31-53

17. HAREWOOD G.C., SHARMA V.K., DE GARMO P. Impact of colonoscopy preparation quality on detection of suspected colonic neoplasia. Gastrointest Endosc., 2003, 58: 76-79.

18. BARKUN A., CHIBA N., ENNS R., MARCON M., NATSHEH S., PHAM C. et al. Commonly used preparations for colonoscopy: Efficacy, tolerability and safety: A Canadian Association of Gastroenterology position paper. Can. J. Gastroenterol,. 2006, 20 : 699-712.

19. REX D.K., IMPERIALE T.F., LATINOVICH D.R., BRATCHER L.L. Impact of bowel preparation on efficiency and cost of colonoscopy. Am. $J$ Gastroenterol., 2002, 97 : 1696-700.

20. KURLANDER J.E., SONDHI A.R., WALJEE A.K., MENEES S.B., CONNELL C.M., SCHOENFELD P.S. et al. How efficacious are patient education interventions to improve bowel preparation for colonoscopy? A systematic review. PloS One, 2016, $11: 10$. 